Oliveira, C.A.F. Envolvimento Comunitário no planejamento do Uso Público do Parque Nacional do Pau Brasil: ações para o desenvolvimento humano das comunidades rurais e guias regionais do entorno. Revista Brasileira de Ecoturismo, São Paulo, v.3, n.1, 2010, pp.79-90.

\title{
Envolvimento Comunitário no planejamento do Uso Público do Parque Nacional do Pau Brasil: ações para o desenvolvimento humano das comunidades rurais e guias regionais do entorno
}

\section{Carlos Alfredo Ferraz de Oliveira}

\section{RESUMO}

O Parque Nacional do Pau Brasil (PNPB) está localizado no município turístico de Porto Seguro no extremo sul da Bahia, esta unidade de conservação (UC) por não possuir um plano de manejo e um programa de uso público não é aberta para visitação. Este artigo foi construído utilizando técnicas de observação participante e aplicação de questionários mistos com a finalidade de descrever e refletir sobre as ações iniciais do processo de construção participativa do uso público no PNPB e entorno, promovidas pelo PNPB/ICMBio, Projeto Corredores Ecológico (PCE/BA) e Programa das Nações Unidas para o Desenvolvimento (PNUD). Estas ações tiveram como objetivo iniciar uma co-responsabilidade no planejamento do uso público desta UC realizando oficinas para qualificação de condutores de visitantes do PNPB e entorno, com guias regionais e comunidades rurais, que utilizaram técnicas participativas visando o desencadeamento de mudanças de pensamentos e atitudes individuais e coletivas sobre as temáticas abordadas. Estas resultaram na potencialização de inserção, através de um processo de desenvolvimento humano, de dois agentes sociais na gestação do uso público do PNPB: os guias regionais de Porto Seguro e comunidades rurais do entorno da UC. A reflexão sobre os resultados alcançados com estas ações de desenvolvimento humano oportunizaram indicações de atividades necessárias para continuidade deste processo.

PALAVRAS-CHAVE: Uso Público, Condutores Visitantes, Gestão Participativa

\section{Community Involvement in Planning the Use Public Pau Brasil National Park: Action for Human Development of the Rural Community and Regional Guides in Surrounding Protected Area.}

\section{ABSTRACT}

The Pau Brasil National Park (PBNP) is located in the tourist town of Porto Seguro in the extreme south of Bahia, Brazil; this protected area (PA), for not having a management plan and a program for public use, is not open to visitors. This article was built by using methods of participative observation and application of questionnaires with a view to describing and reflecting on the actions of the process of participatory construction of public use in and around PBNP, promoted by PBNP/ICMBio, Ecological Corridors Project (ECP/BA) and United Nations Development Program (UNDP). These actions had the objective of starting a co-responsibility in the planning of public use of this PA by conducting workshops for the training of guides of visitors PBNP and the surrounding, with regional guides and rural communities, using participatory techniques with the objective of triggering changes in individual and collective thoughts and attitudes on the issues addressed. These resulted in the enhancement of inclusion, through a process of human development, of two social agents in the management of the public use of PBNP: the regional guides in Porto Seguro and the rural communities surrounding the PA. The reflection on the results achieved with these actions of human development subsidized indications of activities necessary to the continuity of the process.

KEYWORDS: Public Use, Visitor Guide, Management Plan. 


\section{Introdução}

Os Parques Nacionais são Unidades de Conservação (UC) federais de proteção integral, que de acordo com o art. $11^{\circ}$ da Lei No 9.985 e Decreto No 4.340, que institui o Sistema Nacional de Unidades de Conservação da Natureza (SNUC), tem como objetivo:

A preservação de ecossistemas naturais de grande relevância ecológica e beleza cênica, possibilitando a realização de pesquisas científicas e o desenvolvimento de atividades de educação e interpretação ambiental, de recreação em contato com a natureza e de turismo ecológico (BRASIL, 2002, p.14).

Nesta categoria, de UC de acordo com o Parágrafo $2^{\circ}$ do Art. 11 do SNUC "a visitação pública está sujeita às normas e restrições estabelecidas no Plano de Manejo da unidade" (BRASIL, 2002, p.14).

O Parque Nacional do Pau Brasil (PNPB) foi criado em 1999, pelo Decreto s/n de 20 de abril deste ano, possui 11.538 hectares e 70 quilômetros de perímetro situado no município de Porto Seguro no extremo sul da Bahia. O principal objetivo da área é proteger um importante remanescente de Mata Atlântica que possui fitofisionomia predominante de Ombrófila Densa com a presença de espécies endêmicas da Mata Atlântica e protegidas legalmente no Brasil sendo uma área prioritária para conservação na região pela sua integridade e qualidade ambiental (IESB, 2002). Esta biodiversidade junto ao relevo e paisagem apresenta potenciais para o desenvolvimento do ecoturismo ${ }^{1}$ como beleza cênica, quedas d'água, rios e trilhas.

O município de Porto Seguro em sua sede e nos distritos Arraial D'Ajuda e Trancoso e no povoado Caraíva tem como uma das principais atividades socioeconômicas o turismo. De acordo com o governo estadual e federal (PRODETUR NE II, 2002) o município está inserido em uma área prioritária para o desenvolvimento do turismo, denominada Pólo de Turismo do Descobrimento ${ }^{2}$. O turismo neste pólo, por razão de sua importância ambiental e cultural, deve ser planejado para servir como fonte e distribuição de renda, instrumento de melhorias sociais para população local e incentivador da conservação dos patrimônios naturais e culturais (PRODETUR NE II 2002, 2003).

Ainda neste município, existem cinco localidades que possuem comunidades com estreitas relações socioculturais e econômicas no meio rural tendo muitas vezes suas propriedades e/ou trabalhos fazendo fronteira com a área do PNPB. Estas cinco localidades são: Vale Verde, Projeto Vale Verde, Coqueiro Alto, Vera Cruz e Boa Esperança.

O PNPB até o momento não possui um plano de manejo, documento técnico onde estabelece o zoneamento da UC e as normas de uso e manejo da área (BRASIL, 2002). A ausência deste documento impossibilitou até o momento a implantação do uso público e o desenvolvimento do ecoturismo no PNPB. Empresários e 
prestadores de serviços de turismo do município de Porto Seguro vêm questionando o órgão responsável pela UC sobre o impedimento do desenvolvimento das atividades turísticas, argumentando que a atividade poderia proporcionar melhorias socioeconômicas na região (OLIVEIRA, 2008).

Os Parques Nacionais de acordo com o capítulo $V$ do SNUC poderão ter um conselho consultivo, formado por representações de órgãos públicos e da sociedade civil organizada atuantes na região, com a competência de participar da elaboração, implementação e revisão do plano de manejo da UC. O PNPB possui um conselho consultivo com a participação de membros de associações representantes das comunidades rurais, das empresas e prestadores de serviço de turismo do entorno. Estes vêm fortalecendo a urgência da elaboração do plano de manejo do PNPB, enfatizando a necessidade deste documento para o desenvolvimento do ecoturismo no interior da UC.

O Ministério do Meio Ambiente em 2006 elaborou as Diretrizes para Visitação em UC's no Brasil com o objetivo de apresentar um conjunto de princípios, recomendações e diretrizes práticas, para servir de norte no planejamento e ordenamento da visitação nestas áreas. Neste documento apresentam diretrizes que enfatizam a necessidade da participação da comunidade local e dos diferentes atores sociais envolvidos diretamente na questão da UC:

Promover e fortalecer a participação e a co-responsabilidade dos atores interessados no planejamento e gestão da visitação, incluindo comunidade local, entidades representativas dos praticantes de atividades recreativas, operadores de turismo, associações locais, entre outros.(BRASIL, 2006, p.16).

No PNPB as comunidades rurais, os empresários e prestadores de serviços do turismo residentes e atuantes no entorno da UC, buscam a implantação do uso público como nova opção de trabalho e renda, sem apresentar conhecimento e reflexão sobre a importância da elaboração e implantação do plano de manejo e especificamente o programa de uso público, parte integrante do plano, como condicionante para conservação da área e sustentabilidade ${ }^{3}$ da própria visitação que poderá iniciar. Este fato resulta em um processo de participação falho, que cumpre apenas a exigência legal, mas não se apresenta como uma proposta de construção participativa com coresponsabilidade dos atores interessados. Ao mesmo tempo o órgão gestor da UC, Instituto Chico Mendes de Conservação da Biodiversidade (ICMBio), desconhece o funcionamento das atividades turísticas de Porto Seguro e as características socioculturais da comunidade rural do entorno ocasionando uma lacuna que atrapalha elaborar ações que promovam o envolvimento efetivo destes diferentes atores no planejamento do uso público.

Considerando os objetivos de conservação do PNPB, a sustentabilidade da visitação e o ecoturismo nesta área pública, a importância econômica do turismo na re- 
gião, as relações espaciais estreitas das comunidades rurais do entorno com a UC observa-se a necessidade de desenvolver um trabalho de gestão coletiva deste patrimônio natural público no que diz respeito à atividade de visitação. De acordo com Lima (2001) a gestão coletiva é um processo que envolve a participação desde a discussão, planejamento, implantação, gerenciamento, monitoramento e avaliação oportunizando a elaboração coletiva de políticas públicas ambientais e de desenvolvimento.

O Projeto Corredores Ecológicos ${ }^{4}$ (PCE) em 2007 junto com o Programa das Nações Unidas para o Desenvolvimento (PNUD), a pedido do ICMBio/PNPB e aprovação do Comitê Estadual da Reserva da Biosfera da Bahia ${ }^{5}$, financiaram duas consultorias: uma para capacitação de condutores de visitantes no PNPB e entorno envolvendo guias regionais ${ }^{6}$ que já atuam na condução de turistas na região e comunidades rurais do entorno da UC; a outra consultoria foi direcionada a capacitação de agentes de viagem do município de Porto Seguro na elaboração e formatação de roteiros ecoturísticos no entorno do PNPB.

Os analistas ambientais do ICMBio/PNPB avaliaram que o momento era oportuno para iniciar, através destas ações de desenvolvimento humano, um processo de gestar participativamente o uso público da UC.

\section{Objetivo}

Este trabalho visa apresentar a metodologia e os resultados e discussões sobre o processo de elaboração participativa do planejamento do uso público do PNPB, iniciado através de ações de desenvolvimento humano que envolveram comunidades rurais e guias regionais do entorno desta UC.

\section{Metodologia: ações e métodos para capacitação de condutores de visitantes do PNPB e entorno}

O ofício de condutores de visitantes em UC's existe em diversas regiões do país, já há alguns anos. Em documentos e programas do governo federal como as Diretrizes para Visitação em Unidades de Conservação e o Programa de Normalização do Turismo (ABNT/MTur ${ }^{7}$ ) o condutor é recomendado como importante profissional do turismo nestas áreas. Mesmo com este reconhecimento ainda existem problemas na regularização e conquista de espaço desta função na cadeia produtiva ${ }^{8}$ do Turismo, mais este problema, pela sua complexidade, é importante ser tratado em outro trabaIho com foco específico para o assunto. Ressalto apenas que de acordo com as diretrizes para visitação em UC's (MMA, 2006) o condutor de visitantes em UC's tem um importante papel na experiência do visitante, proporcionando incremento educativo, interpretativo, e segurança durante a visita. 
Foram realizadas reuniões para elaboração e discussão do projeto pedagógico das oficinas com os servidores públicos da UC e os membros do seu conselho consultivo. Durante a construção participativa do projeto pedagógico foi decidido que era necessário realizar atividades didáticas e aplicação de técnicas participativas em formato de oficinas direcionadas para comunidade rural e outras para os guias regionais por tratarem de públicos diferenciados tanto no tipo de conhecimentos que possuíam como modo de aprendizagem e de interesses a respeito da visitação no PNPB com previsão ao final do trabalho de uma oficina que unissem os dois públicos e mais um terceiro, as agências de viagem e turismo participantes da outra consultoria, para a construção de um produto final que integrasse os diferentes conhecimentos, pontos de vistas e interesses.

Foi realizada uma oficina, direcionada para os guias regionais, durante o período de 3 dias totalizando vinte quatro horas de duração, com a participação de dezenove oficineiros, dividido em dezesseis horas de atividades em sala de aula e 8 horas em campo especificamente nas áreas de Mata Atlântica no entorno do PNPB. A oficina direcionada às comunidades rurais ocorreu durante o período de 5 dias com trinta e duas horas de duração e envolveu a participação de vinte e oito membros das comunidades rurais. As atividades foram divididas em dezesseis horas em sala de aula e dezesseis horas em campo nas áreas de Mata Atlântica e nos povoados do entorno do PNPB.

Durante as oficinas foram utilizadas técnicas participativas para a transmissão e obtenção de informações, provocação de reflexões sobre as condições socioambientais do PNPB e entorno, e envolvimento da co-responsabilidade e participação do planejamento da visitação do PNPB. Estas técnicas visam o desencadeamento de mudanças de pensamentos e atitudes individuais e coletivas sobre as temáticas abordadas. As técnicas utilizadas foram baseadas na descrição de Drumond (2002) com adaptações necessárias para a localidade e temas trabalhados. Foram utilizadas as seguintes técnicas: exposição dialogada, apresentação de slides sobre temas chaves, tempestade de idéias, dinâmicas de sensibilização ambiental, travessia (desenho de roteiros), matriz de opções.

Baseados na pesquisa bibliográfica (GIL, 1987) realizada sobre o PNPB e visitação em UC's, e nas reuniões com o conselho consultivo do PNPB, os temas escoIhidos e abordados nas oficinas foram: ecologia, meio ambiente e UC's: histórico, conceitos e legislação; PNPB e o seu ecossistema, introdução ao ecoturismo, técnicas de condução de visitantes em trilhas, técnicas de interpretação ambiental, monitoramento de impacto socioambiental na visitação, planejamento e manejo de trilhas na Mata Atlântica, planejamento da visitação em UC's.

Durante as oficinas foi aplicada a técnica de observação participante (JONES, 1993) classificada como participante observador (GOLD, 1958) com objetivo de compreender e interpretar as experiências ocorridas com os atores sociais envolvidos neste processo inicial. 
Foram elaborados e aplicados, ao final das oficinas, questionários mistos (ALENCAR, 2003) com o objetivo de levantar o perfil profissional dos oficineiros e conhecer suas opiniões sobre as ações futuras necessárias para o planejamento do uso público no PNPB.

\section{Resultados e Discussões das oficinas de condução de visitantes no entorno do PNPB}

Os locais para as atividades em campo foram: Reserva Particular do Patrimônio Natural (RPPN) Veracel, Reserva Indígena Aldeia Velha (etnia Pataxó) e ruas históricas do povoado Vale Verde.

\section{a) Oficinas guias regionais}

Durante as oficinas ocorreram discussões e reflexões sobre o turismo no município onde foi demonstrado o interesse dos participantes em diversificar os roteiros turísticos de Porto Seguro, o que poderia aumentar e diversificar o público na região, enfatizando que as potencialidades ecoturísticas nas áreas naturais do município não fazem parte dos roteiros e quando fazem são trabalhadas com banalização e massificação dos serviços. As causas apontadas foram que por razão da tipologia turística desenvolvida é o turismo sol e praia os empresários do turismo e o poder municipal local desconhecem e/ou não acreditam em novas oportunidades. Apontaram que este fato limitaria e dificultaria o planejamento e a sustentabilidade do turismo no PNPB.

Foi observada, nos resultados obtidos com as aplicações das técnicas participativas, a necessidade de um fortalecimento organizacional dos guias regionais no intuito da conquista de espaço e representatividade no setor turístico da região podendo demonstrar o valor e a qualidade dos seus trabalhos e propor novas ações para o turismo na região.

As atividades realizadas em espaço interno e externo resultaram, além dos conhecimentos adquiridos sobre condução de visitantes em UC's, na sensibilização dos guias regionais participantes em pensar e planejar o turismo não só em áreas naturais como também em todo o município com princípios e objetivos de sustentabilidade e que para isso concluíram que são necessárias ações de envolvimento e compromisso de diferentes atores inclusive deles que assumiram terem problemas de organização dificultando a representação e as conquistas dos objetivos individuais e coletivos.

\section{b) Oficinas comunidades rurais}

Os participantes da comunidade rural apresentaram conhecimentos locais sobre a Mata Atlântica e a história dos povoados em que residem demonstrando uma ótica diferenciada dos guias regionais, sobre os patrimônios naturais e culturais da 
área, fator que precisa ser considerado e ressaltado nas suas características profissionais de condutor o que poderá valorizá-los nesta função. Este conhecimento popular constatado foi utilizado durante aplicações das técnicas participativas, como instrumento de envolvimento maior dos oficineiros sobre os temas socioambientais trabaIhados, fazendo uma relação com a memória e identidade social.

A etapa da oficina realizada na Reserva Indígena Aldeia Velha os oficineiros observaram como o conhecimento popular da Mata Atlântica e da história local enriquece o trabalho na condução de visitantes. Nesta foi trabalhada a técnica da travessia onde foi possível desenhar roteiros em trilhas que os condutores identificaram a oportunidade de apresentar os seus conhecimentos e características históricoculturais integrada com as curiosidades do ambiente natural durante o trabalho de condutor. Esta percepção obtida serviu para desenvolver em grupo um trabalho de planejamento de roteiros ecoturísticos em trilhas da Mata Atlântica. Os roteiros que resultaram do trabalho foram utilizados na oficina de encerramento junto com as agências de turismo participantes deste processo inicial.

Ao final da oficina foi identificado, através de avaliações, o aprimoramento do conhecimento sobre técnicas de condução e o uso público em UC's. Os participantes demonstraram aptidão e interesse em exercer a profissão ressaltando a necessidade de realizarem cursos de primeiros socorros e resgate em áreas remotas, e criarem uma associação como forma de organização e fortalecimento para a conquista de espaço na região como condutores de visitantes.

\section{c) Oficina com as agências de turismo da região}

A oficina teve a finalidade de oportunizar um encontro para trocas produtivas entre os atores envolvidos neste processo de capacitação em ecoturismo, promovido pelo PNPB e os apoios dos parceiros, através da realização de um exercício que instigou a necessidade de inventariar e planejar o uso sustentável dos recursos turísticos naturais e culturais do PNPB e entorno, envolvendo a comunidade rural e local representada pelos condutores e guias regionais, e as empresas de turismo da região, representadas pelos agentes de viagem, sendo estes inicialmente os principais interessados na implantação do ecoturismo nesta UC.

Os produtos finais desta oficina demonstraram a compreensão básica do planejamento de atividades ecoturísticas em um Parque Nacional e entorno e serviu como fonte de informações para o ICMBio/PNPB utilizar no envolvimento destes atores no planejamento do uso público.

\section{d) Perfil profissional dos oficineiros}

Os dados coletados sobre o perfil dos oficineiros servem como informações vá- 
lidas para ICMBio/PNPB conhecer os atores que necessitam serem envolvidos no planejamento do uso público do PNPB.

Perfil guias regionais: $70 \%$ possuem mais de 5 anos de experiência, $15 \%$ de 3 a 5 anos e $15 \%$ de 1 a 3 anos; $100 \%$ atuam nos atrativos recife de fora e centro histórico de Porto Seguro, $70 \%$ manguezais e rios e 30\% em trilhas da Mata Atlântica; $60 \%$ trabalham como autônomo sem vinculo com nenhuma agência de turismo, $20 \%$ com vínculo e $20 \%$ outros.

Importante ressaltar o dado que apresenta apenas dois atrativos no qual todos os guias entrevistados atuam, demonstrando oportunidades de diversificação nas experiências do guia e nos roteiros mais vendidos em Porto Seguro, fortalecendo os apontamentos feitos pelos guias regionais durante as oficinas sobre o mercado limitado, comparando com as potencialidades existentes na região.

Perfil comunidade rural: as profissões apresentadas foram: $30 \%$ agricultor, $20 \%$ brigadista (combate a incêndio florestal), $20 \%$ pescadores e 30\% estudantes. As principais expectativas dos oficineiros como condutores foram: $40 \%$ trabalho, $30 \%$ resgatar e interpretar os fatores histórico-culturais da região em que vivem para os visitantes; $20 \%$ aprendizagem com a natureza; $10 \%$ apoio institucional para organização social da comunidade rural como condutores do PNPB.

\section{e) Envolvimento dos condutores na gestão do uso público da UC}

Com o questionário aplicado no final da oficina foi levantado quais são as sugestões dos oficineiros sobre as ações a serem feitas visando gestão coletiva do uso publico do PNPB. As sugestões foram: participação efetiva das comunidades do entorno e do conselho consultivo em todas as etapas, capacitar a comunidade sobre a temática UC e ecoturismo para a participação mais efetiva e produtiva, objetivar no planejamento a geração e distribuição de renda local, diversificar as opções recreativas para os visitantes, trabalhar o planejamento da interpretação ambiental nas trilhas utilizando temas da história e cultura da região, ordenamento turístico através do cadastramento das agências e guias/condutores que passaram pelas capacitações realizadas sendo permitida a operação e execução das atividades turísticas apenas por estes, identificar as singularidades do PNPB.

Resultados obtidos com as ações de desenvolvimento humano envolvendo diferentes atores sobre uma mesma temática, ecoturismo em UC's, fortalece um processo que Lopes (2006) denomina por "ambientalização" que corresponde a interiorização das questões ambientais como questão pública neste caso destas comunidades rurais, empresários e profissionais do Turismo que residem e trabalham no entorno do PNPB e pouco sabiam e refletiam sobre as relações estreitas entre melhoria socioeconômica e conservação ambiental. 
A mobilização e envolvimento destes atores foram fortalecidas pelas atividades relacionarem a história e cultura local da região, principalmente junto às comunidades rurais, o que facilitou a participação e o sentimento de pertencimento na construção deste processo inicial (LOPES, 2006).

\section{Conclusão}

Os trabalhos realizados, através das oficinas de capacitação, iniciaram o envolvimento de três atores sociais na gestão do uso público do PNPB. Os atores já envolvidos profissionalmente com o Turismo demonstraram-se descontentes com o turismo da região principalmente por sua tipologia de sol e praia e características massificantes e exploradoras tanto do turista quanto dos profissionais da cadeia produtiva do setor. Com as informações e ações construídas durante as oficinas foi reconhecido que para mudança desta situação profissional é necessário união e organização dos guias regionais buscando representatividade no setor. Sobre as transformações sugeridas como necessárias para sustentabilidade do turismo em Porto Seguro e futuramente no PNPB, foi destacado a necessidade de envolvimento maior dos atores dos poderes públicos municipais e estaduais, empresários do setor e comunidade local organizada e que para isto são necessárias ações de desenvolvimento humano, como esta realizada, e construção participativa de políticas públicas direcionadas para democratização do setor turístico, ambiental e cultural de Porto Seguro.

Ao final do trabalho foi possível sugerir ações para o andamento no processo iniciado de gestão participativa do uso público no PNPB:

- Priorizar a continuidade da capacitação e a integração com a UC dos condutores envolvidos neste processo oportunizando suas participações no planejamento e implantação do uso público do PNPB;

- Planejar com a participação dos condutores o uso dos atrativos naturais e culturais considerando os conhecimentos populares e a cultura das comunidades rurais do entorno para elaboração dos temas interpretativos e as atividades ecoturísticas a serem realizadas;

- Incentivar os elementos culturais das comunidades rurais do entorno integrando estes aos atrativos ecoturísticos do PNPB;

- Promover ações que divulguem a importância e discutam as ações necessárias para o planejamento e implantação do ecoturismo na região e no entorno do PNPB;

- Apoiar a viabilização de capacitações contínuas e graduais dos condutores referentes à segurança dos visitantes como primeiros socorros e resgate em áreas remotas e que estes sejam adaptados ao grau de conhecimento do público e a realidade da infra-estrutura de atendimento hospitalar da região; 
- Elaborar com a participação dos condutores um plano de emergência para visitação do PNPB;

- Apoiar a capacitação dos condutores em planejamento e manejo de trilhas em Mata Atlântica, viabilizando sua participação no planejamento, implantação e manutenção das trilhas no PNPB;

- Promover capacitações específicas para os condutores do PNPB que contemplem o conhecimento popular e científico sobre os atrativos e as atividades possíveis de serem realizadas neles, como também as regras e condutas estabelecidas para visitação nestes;

- Incentivar a organização dos condutores de visitantes do PNPB;

- Considerar a necessidade de cadastramento de todos os condutores que queiram atuar no PNPB;

- Estabelecer critérios mínimos no plano de uso público para o cadastramento dos condutores e que estes contemplem a necessidade de capacitações específicas já iniciadas neste processo;

- Promover a integração das agências de turismo participantes deste processo com os condutores facilitando parcerias enriquecedoras para ambas as partes e o planejamento integrado do uso público do PNPB;

- Incentivar a elaboração de roteiros ecoturísticos que integrem os atrativos do PNPB com o seu entorno fomentando a geração e distribuição de renda para as localidades rurais de entorno e oportunizando a diversificação recreativa e educativa na experiência do visitante;

- Divulgar e incentivar aos agentes de viagens e os visitantes sobre a importância de realizar visitas ao PNPB acompanhados dos condutores, promovendo assim a oportunidade de trabalho e geração de renda a estes e a superação das expectativas e a sensibilização ambiental dos visitantes;

Estabelecer no plano de uso público métodos participativos de monitoramento de impactos socioambientais que incluam a participação dos condutores.

\section{Referências Bibliográficas}

ALENCAR, E. Pesquisa Social e Monografia. Lavras: UFLA/FAEPE, 2003.109p.

BRASIL. Lei no 9.985, de 18 de julho de 2000; decreto no 4.340, de 22 de agosto de 2002. Institui o Sistema Nacional de Unidades de Conservação da Natureza SNUC. 5. Ed. Aum. Brasília: MMA/SBF, 2002. 56p.

DRUMOND, M. A. Participação comunitária no manejo de Unidades de Conservação: manual de técnicas e ferramentas. Belo Horizonte: Instituto Terra Brasilis de 
Desenvolvimento Sócio-Ambiental, 2002.

GIL, A. C. Métodos e técnicas de pesquisa social. São Paulo: Atlas, 1987.

GOLD, R. L. Roles in sociological field observations. Social forces, v.36, n.3, p.217223, mar. 1958.

IESB. Abordagens ecológicas e instrumentos econômicos para o estabelecimento do corredor do descobrimento. Ilhéus - BA: PROBIO/MMA, 2002.

JONES, P. Studying society: sociological theories and research pratices. Londres: Collins, 1993.

LIMA, R. B. O Princípio da Participação em Gestão Ambiental: A fronteira entre gerir e gestar. In: IV Encontro da Sociedade Brasileira de Economia Ecológica, 2001, Belém. Anais do VI Encontro da Sociedade Brasileira de Economia Ecológica, 2001.

LOPES, J. S. L. Sobre processos de "ambientalização" dos conflitos e sobre dilemas da participação. Horizontes antropológicos. Porto Alegre, ano 12, n. 25, p.31-64, jan./jun. 2006

BRASIL. MMA . Diretrizes para visitação em Unidades de Conservação. Brasília: MMA, 2006, 70p.

BRASIL. MTur. Regulamentação, normalização e certificação em turismo de aventura. Brasília: Ministério do Turismo, 2005.

OLIVEIRA. C. A. F. Relatório Técnico: oficina de condutores de trilhas na Mata Atlântica e do Parque Nacional do Pau Brasil. Porto Seguro: PNUD/PCE, 2007.

PCE. Síntese do processo de definição e planejamento dos corredores prioritários no Espírito Santo. Cariacica: PCE, 2006.

PRODETUR NE II. Plano de Desenvolvimento Integrado do Turismo Sustentável - Costa do Descobrimento. Fundação Getúlio Vargas/HVS International/Governo do Estado da Bahia. São Paulo, 2002.

SACHS, I. Estratégias de transição para o século XXI. In: BURSZTYN, Marcel (org.). Para pensar o desenvolvimento sustentável. São Paulo: Brasiliense, 1993. p. 2955.

TOMELIN, C. A. Mercado de agências de viagens e turismo: Como competir diante das novas tecnologias. São Paulo : Aleph, 2001. 
NOTAS:

${ }^{1}$ Segmento turístico realizado em patrimônios naturais e culturais, que incentiva sua conservação e a formação de uma consciência ambientalista, promove o bem-estar das populações envolvidas (MICT/MMA, 1994).

${ }^{2}$ O Pólo Turístico do Descobrimento é formado pelos municípios da área costeira do extremo sul da Bahia onde o zoneamento foi realizado durante o a implantação do PRODETUR/NE com a finalidade de integrar a cadeia produtiva do Turismo das zonas turísticas do estado da Bahia (PRODETUR/NE II 2002, 2003 ).

${ }^{3} \mathrm{O}$ termo sustentabilidade e desenvolvimento sustentável referidos neste trabalho está baseado nas cinco dimensões do ecodesenvolvimento apontado por Sachs (1993): sustentabilidade social, econômica, ecológica, espacial e cultural.

${ }^{4}$ Projeto do MMA junto com os órgãos ambientais dos estados participantes que tem como objetivo reduzir a fragmentação dos remanescentes florestais, através do aumento da conectividade entre eles (PCE, 2006).

${ }^{5}$ Instância de deliberações de ações planejadas pelo PCE/BA (PCE, 2006).

${ }^{6}$ Profissional do Turismo que, devidamente cadastrado no órgão oficial de Turismo (nacional/estadual), exerça atividade de acompanhar, orientar e transmitir informações a turistas e grupos de visitantes, em todo território do Estado da Bahia.

${ }^{7}$ Programa entre o Ministério do Turismo (MTur) e Associação Brasileira de Normas Técnicas (ABNT) que tem o objetivo de estabelecer participativamente as normas e regras para o correto desenvolvimento das diferentes atividades turísticas no Brasil podendo fundamentar a certificação de produtos turísticos no país (MTur, 2005).

${ }^{8}$ Segundo o Ministério do Desenvolvimento, Indústria e Comércio Exterior (apud Tomelin, 2001) conceitua a cadeia produtiva como: "o conjunto de atividades (elos) que se articulam progressivamente desde os insumos básicos até o produto final".

Carlos Alfredo Ferraz de Oliveira: Mestrando em Cultura e Turismo pela Universidade Estadual de Santa Cruz (UESC). Bolsista da Fundação de Amparo à Pesquisa do Estado da Bahia - FAPESB.

Email: cferrazgp99@yahoo.com.br

Link para o currículo Lattes: http://lattes.cnpq.br/1561110382196376

Data de submissão: 17 de outubro de 2009.

Data do aceite: 04 de dezembro de 2009. 